\title{
El PARADIgMA COMÚN de LOS HISTORIADORES DEL SIGIO XX
}

Carlos Barros*

Antes de preguntarnos adónde va la historia que hacemos los historiadores habría que pararse a diluciciar de dónde viene. (1) Más allá y más acá de las grandes escuelas historiográficas del siglo $\mathrm{XX}$, nos cuesta reconocer lo que tuvimos $\mathrm{O}$ tenemos en común historiadores y especialidades históricas tan dispares, especialmente en tiempos de fragmentaciones e incertidumbres como los presentes.

La actual crisis de identidad de la historia hace, pues, imprescindible un balance finisecular: urge recomponer el acervo común de los historiadores, valorando los éxitos y, sobrc todo, los fracasos colectivos, con el fin de comprender el aparente callejón sin salida en que nos encontramos, y de entrar en el siglo XXI rearmados de moral y científicamente. En resumen, hay que aplicar el método de la historia a la propia escritura de la historia, tarea sorprendentemente inusual, y hasta marginal, en el quehacer de los historiadores hasta hace bien poco.

La falta de estudios, reflexiones y debates, sobre historiografia, metodología y teoría de la historia, es precisamente una de las características del viejo, y hoy cuestionado, paradigma común que contribuye a explicar tanto las dificultades que tenemos para su explicitación retrospectiva como su reciente caída irreversible. Convertir a los historiadores y sus obras, a las corrientes historiográficas y sus crisis, a los valores y las prácticas de la profesión, en objeto de investigación científica (y de debate), esto es, sabiendo que lo que se dice no siempre coincide con lo que se es y con lo que se hace, contextualizando nuestra problemática, es una necesidad que empicza a tener adecuado reflejo en congresos, revistas y libros, sintoma de

* Universidad de Santiago de Compostela, España. 
una creciente toma de conciencia de los historiadores acerca del punto crítico en que nos encontramos.

\section{De la historia de la ciencia a la historiografia}

La escasa inteligibilidad de las creencias, las prácticas y la evolución de la ciencia ha sido un problema general hasta que se desarrolló la historia (y la sociologia) de la ciencia, que rivaliza con la filosofia de la ciencia en la redefinición del status epistemológico del saber científico. La historia de las ciencias sociales y humanas en general, y la historia de la historia en particular, dejarán de ser literatura accesoria en la medida que asuman críticamente los avances de la historia de la ciencia, que ha constatado hace ya bastante tiempo cómo los científicos "son poco mejores que los legos en la materia para caracterizar las bases establecidas de su campo, sus problemas y sus métodos aceptados".(2)

La invisibilidad de los paradigmas compartidos por los historiadores es, por tanto, un problema asimismo compartido con las demás ciencias que Thomas $\mathrm{S}$. Kuhn ha resuelto brillantemente definiendo el concepto de paradigma y poniendo al descubierto el papel central de la comunidad científica en la validación del conocimiento científico, cuyos paradigmas no son eternos sino que mudan a través de rupturas revolucionarias, diferenciando - demasiado netamente-los periodos de ciencia normal de los periodos de ciencia extraordinaria: crisis, debate y sustitución de paradigmas.

La aplicación de los descubrimientos de Kuhn a las ciencias sociales y humanas se infiere de sus propias deudas explicitadas con la historia, la sociología, la psicología social y la epistemología, ${ }^{(3)}$ a la hora de estudiar las ciencias naturales - el objeto principal de sus análisis-, de la propia experiencia de la historia de la historiografia, y, en definitiva, de la madurez como ciencia social adquirida por la historia a lo largo del siglo XX: su propia expansión implica la existencia de un vigoroso paradigma común.

Kuhn es un físico que deviene historiador para tratar de comprender las ciencias de la naturaleza: "Asombrado, me di cuenta de que la historia podía serle útil al filósofo de la ciencia"; ${ }^{(4)}$ presume de ser miembro de la Asociación Norteamericana de Historia y no de Filosofia, y de que sus estudiantes desean ser historiadores y no filósofos. ${ }^{(5)}$ Cuando menos debemos plantearnos devolver a la historia, con intereses, lo que Kuhn aprendió de la historia. A sus críticos asegura Kuhn que ejerce de historiador para saber epistemologia; ${ }^{(6)}$ obviamente, es un historiador de nuevo tipo que - inclusive respecto de la nueva historia- no desprecia la teoría: considera ésta su meta final.

En un primer momento, la historia copió de la física clásica, determinista, para ser considerada ciencia, dejando atrás, conceptos como el cambio y la subjetividad en el proceso de conocimicnto; ahora, la física aprende con Kuhn de la vieja 
historia (y también de Darwin) que el desarrollo científico no es acumulativo sino que avanza gracias a "rupturas revolucionarias", se busca el paralelismo con las revoluciones históricas para entender las revoluciones científicas, episodios en los "que un antiguo paradigma es reemplazado, completamente o en parte, por otro nuevo e incompatible", (7) y se toma muy en consideración el papel de la mentalidad colectiva en el comportamiento de las comunidades científicas, tanto en los períodos acumulativos de ciencia normal como en tiempos de crisis y muda de paradigmas. Con todo, las influencias externas de los factores sociales y culturales en el devenir de las comunidades científicas (notorias en el caso de las ciencias sociales y humanas) son por regla general desatendidas, aunque no negadas, por Kuhn en sus trabajos, concluyendo que la evolución de las ciencias desarrolladas se da con "relativa independencia del medio social".(8) Su gran contribución es poner de relieve el rol de las comunidades científicas, por un lado, y de las revoluciones paradigmáticas, por el otro, el contexto y la sincronía debemos añadirlos nosotros, los historiadores generales de la sociedad y de la mentalidad.

Para reconstruir una historia de la ciencia que no sea lineal ni acumulativa. Kuhn se sirve de un concepto narrativo de la historia, pero rechaza la mera crónica y resalta su naturaleza explicativa ("mostrar no únicamente hechos sino también las conexiones que hay entre ellos"), incluso no descarta la existencia de leyes de conducta social aplicables a la historia, aunque éstas "no son esenciales para su capacidad explicativa"; a diferencia de la física que cuando se empieza a escribir ya se acabó el proceso de investigación, para la historia — según Kuhn- es fundamental el momento de la narración, que forma parte de la investigación. ${ }^{(9)}$ Sin embargo, el paradigma dominante, en los años ' 60 y ' 70 , entre los historiadores, no era el narrativo, sino el estructural-funcional, la innovación que propone Kuhn subvierte, pues, tanto al concepto establecido de historia como al concepto de ciencia en general. Por supuesto, no cabe confundir la historia narrativa con ambiciones explicativas y epistemológicas de Kuhn con el conocido enfoque positivista de "examinar textos, extraer de ellos los hechos pertinentes, y relatarlos con gracia literaria, más o menos en orden cronológico", idea decrépita de la historia que "no tomaba muy en serio" nuestro historiador de la ciencia. ${ }^{(10)}$ Conque la historia narrativa-explicativa de Kuhn pertenece más al futuro que al pasado de nuestra disciplina, y viene a confluir con los esfuerzos de otros filósofos (Ricoeur) e historiadores (Lefebvre, Topolsky) por dar a luz una nueva historia narrativa.

\section{Nociones de paradigma}

La palabra paradigma tiene un doble sentido para Kuhn, el específico de ejemplo y otro más genérico - y original- que se refiere a los compromisos compartidos por una comunidad científica dada. (11) Se ha ido imponiendo la segunda acepción sobre la significación primigia y literal que asimila paradigma a 
modelo y ejemplo (como las conjugaciones estándar de los verbos regulares). El intento del propio autor, en 1969, de sustituir el sentido amplio de paradigma por la noción de matriz disciplinar, ${ }^{(12)}$ para evitar confusiones y recoger el carácter plural đe los elementos teóricos, metodológicos y normativos que gozan del consenso de los especialistas, no ha tenido éxito porque lo revolucionario de la aportación de Kuhn está precisamente en la amplitud con que aplica el término paradigma, a la vez matriz disciplinar y referencia ejemplar. Lo más claro es singularizar con el adjetivo "común" el paradigma plural - los paradigmas compartidos-que asume, más o menos explícitamente, la mayoría de los miembros de una especialidad profesional, científica.

Se sobreentiende entonces que el paradigma común, general, de una comunidad científica contiene por su parte paradigmas particulares relacionados entre sí, siendo muy importantes los modelos-ejemplares, realizaciones científicas que ofrecen soluciones a problemas concretos y que son aceptados universalmente (como el péndulo de Foucault para demostrar el movimiento de la tierra); los paradigmasejemplos actúan por semejanza y emulación, y son fundamentales en la enseñanza de una disciplina y en la iniciación a la investigación. Los modelos ejemplares compartidos en historia vienen a ser las obras clásicas de cada disciplina, subdisciplina o temática, si bien tendrían menos importancia que la resolución de problemas-tipo en fisica, por ser más abundantes entre los historiadores profesionales las reglas compartidas. (13) En todos los casos, "es la posesión de un paradigma común lo que constituye a un grupo de personas en una comunidad científica, grupo que de otro modo estaría formado por miembros inconexos". (14) Como cada científico no puede construir su campo de actuación desde los cimientos: sin paradigmas consensuados no hay verdaderamente ciencia como obra colectiva. El uso del concepto de paradigma según Kuhn se está generalizando en los últimos años del siglo, en las ciencias naturales y sociales, en los ambientes académicos y también en el lenguaje culto de algunos medios de comunicación.

Una comunidad científica está constituida por aquellos profesionales que practican una especialidad, han recibido parecida educación y leído los mismos libros, enseñan colegiadamente a sus sucesores, mantienen cierta comunicación interna a través de sociedades, congresos, revistas y otras vías menos formales, sobre la base de una relativa - por su diversidad - pero efectiva unanimidad de juicios sobre el oficio. ${ }^{(15)}$ Para Kuhn los miembros de una comunidad científica determinada proporcionan "el único auditorio y el único juez a los trabajos de dicha comunidad".(16) Los paradigmas compartidos lo son de forma más tácita que explícita, más práctica que teórica; no están especificados con toda precisión ni, por descontado, exentos de desacuerdos y conflictos internos; se trata de creencias aceptadas (su estabilidad nos faculta para hablar de valores) que permiten a los miembros de la comunidad seleccionar, evaluar, criticar e interpretar; sus elementos provienen tanto de la teoría como de la práctica, de la propia disciplina como de otras, del conocimiento científico como del conocimiento corriente, etc. ${ }^{(17)}$ 
Estos valores comunes a toda una especialidad científica no son idénticos de una comunidad a otra, de una época a otra, ${ }^{(18)}$ tienen su propia especificidad e historia que hay que examinar a fin de superar el síndrome académico del compartimento: la ilusión etnocéntrica - cuando no egocéntrica- de que no hay nada más allá de la torre de marfil de la escuela, del área de conocimiento, de la línea o del grupo de investigación, del "yo" particular, como si fuera del propio - y seguro- ámbito de actuación todo fuese discrepancia, confusión, eclecticismo... El reconocimiento explícito de la existencia de activos paradigmas compartidos que fueron - y en algún sentido aún son-, objetivamente, más importantes que la pertenencia a una determinada escuela, especialidad, tradición nacional, filosofia o ideología política, es hoy un ejercicio de modestia, intelectual y científica, que tenemos que practicar los historiadores.

Las comunidades científicas no están aisladas entre sí, mantienen relaciones de inclusión e interdependencia: los historiadores contemporáneos se consideran parte de los científicos sociales, y éstos a su vez de los científicos en general (comandados por las ciencias de la naturaleza). El paradigma imperante en las ciencias naturales condiciona el paradigma de las ciencias sociales y humanas, que a su vez sobredetermina el paradigma común de los historiadores. Las líneas de influencia actúan también - cada vez más- en sentido contrario (la historia y la fisica: Kuhn, por ejemplo).

La existencia de un paradigma común no implica, ordinariamente, una teoría común. Sobre las teorías dice Kuhn: "tales construcciones tradicionales son, a la vez, demasiado ricas y demasiado pobres para representar lo que los científicos tienen in mente cuando hablan de su adhesión a una teoría particular"; (19) y, además, pocas ciencias sociales disponen de una teoría bien articulada y ampliamente aceptada. ${ }^{(20)}$ La teoría marxista de la historia ha sido, sin duda, la más admitida entre los historiadores del siglo XX, pero sería excesivo, y faltar a la verdad, considerarla la teoría común de algo tan amplio como los Annales, el materialismo histórico y el neopositivismo, las tres tradiciones que han convergido en la segunda posguerra para formar nuestro paradigma común diverso y plural.

Los valores pueden ser compartidos por hombres que difieren en su aplicación; el paradigma común comporta un grado de tolerancia hacia la desviación individual y colectiva; ${ }^{(21)}$ la coincidencia en aspectos principales de cómo entender el oficio no es, por consiguiente, lo mismo que la identidad de criterios; ${ }^{(22)}$ en suma, la diversidad es la norma y no la excepción de un paradigma científico realmente operativo, porque la ciencia normal no es una empresa única, monolítica y unificada: "viendo todos los campos al mismo tiempo, parece más bien una estructura desvencijada con muy poca coherencia entre sus diversas partes".(23) Esta flexibilidad paradigmática no es un invento de Kuhn, resulta de cualquier aproximación sociológico-histórica a las comunidades científicas reales, las cuales no se rigen tanto por reglas y teorías rígidas como por paradigmas compartidos que, ciertamente, han de guardar el grado de coherencia y compatibilidad suficien- 
tes como para garantizar un marco común y eficaz de trabajo, que asegure que las inevitables polémicas no afectarán a la práctica en períodos de ciencia normal.(24) La historia y la sociología de la ciencia han echado abajo, en consecuencia, esa falsa y simplificadora alternativa, tan corriente, de rigidez teórica o eclecticismo vulgar. Bien entendido que la unidad, flexibilidad y diversidad detectadas no significan debilidad: no hay más que ver lo mucho que les cuesta a los científicos abandonar sus creencias paradigmáticas. Resumiendo, la existencia de un paradigma común no presupone una única lectura: "puede, por consiguiente, determinar simultáneamente varias tradiciones de ciencia normal que, sin ser coextensivas, coinciden". (25) Comprenderlo es aprender a pensar de otra manera, es dejar de engañarnos a nosotros mismos, es rebasar una extendida "falsa conciencia" sobre cómo funciona verdaderamente nuestra disciplina.

\section{Nuestro territorio común}

El contenido complejo de unidad-pluralidad de la noción de paradigma, ¿cómo se aplica a la historia? Si consultamos las memorias de las oposiciones a profesores numerarios encontraremos, usualmente, referencias conjuntas tanto a la escuela de Annales como al materialismo histórico - con la oportuna muestra de respeto positivista por las fuentes-, citas rituales a significativos autores y obras, pretendiendo con frecuencia el concursante cierta diversidad que satisfaga al previsible variado tribunal fruto del sorteo correspondiente. Una manera, pues, de acceder al paradigma común de los historiadores son estos proyectos docentes. Pero el enseñante fue antes enseñado y aprendió los fundamentos de la disciplina en libros de texto, ${ }^{(26)}$ clases magistrales, lecturas obligatorias, seminarios, clases prácticas. Vocabulario de la disciplina, frases del tipo "la función del historiador no es juzgar los hechos históricos", reconocimiento de los profesionales más aceptados y de las investigaciones y síntesis consideradas maestras, calificación negativa o positiva de una interpretación, tema o método de investigación: todo ello se aprende en las facultades de historia, dentro y fuera de las aulas. El paradigma subyacente se refleja en los programas de las asignaturas y en sus manuales de apoyo: todos bastantes parecidos. Los profesores difunden y defienden en las clases el paradigma establecido, aun en tiempos de crisis, más allá incluso de su opinión personal, que si acaso se refleja más en la originalidad de sus trabajos de investigación, y ello no siempre. Las múltiples traducciones de obras de síntesis y de estudios monográficos (mayoritariamente del francés y del inglés) han unificado a lo largo de los años el territorio común, nacional e internacional, de los historiadores alrededor (pero no sólo) de las principales escuelas y tradiciones. Con los escasos pero cruciales artículos o libros que tratan de historiografia, metodología y teoría de la historia (la filosofia de la historia viene siendo, a pesar de todo, más dedicación de filósofos que de historiadores), como la Apologie pour l'Histoire ou Métier 
d'historien de Marc Bloch (París, 1949) o What is history? de Edward H. Carr (Londres, 1961), reeditados una y otra vez en los idiomas principales de Occidente, se completan los mecanismos de homogenización y difusión del paradigma común de los historiadores del siglo XX, que, insistimos, es dado a conoćer más a través de sus realizaciones prácticas que teóricamente, lo cual dificulta sobremanera su identificación pero no así su eficacia ejemplarizante y homologadora.

En los manuales de historia dirigidos a los estudiantes, y demás libros-síntesis de historia, el paradigma común está implícito, se muestra en ellos la obra final no las herramientas utilizadas, porque no se habla de conceptos, métodos y valores historiográficos, por consiguiente no suele haber referencias a las revoluciones historiográficas, ¿con el objetivo de que la historia de la historia parezca lineal-acumulativa, como denuncia Kuhn para las ciencias naturales? (27) $\mathrm{Si}$ bien la historia del siglo XX participa del paradigma ilustrado de una ciencia acumulativa que progresa linealmente, los textos de reflexión historiográfica tienden a lo contrario: destacan los cortes historiográficos y disimulan el hilo conductor, la continuidad sea diacrónica sea sincrónica entre las diferentes escuelas, la existencia en definitiva de un patrimonio común. ${ }^{(28)}$ De ahí la falta de precedentes, y las dificultades con que nos encontramos, para la reconstrucción que queremos - sobre nuevas bases- de un activo largamente compartido, lo que denominamos usualmente como la ciencia de la historia, la historia científica, la historia como ciencia social, el paradigma establecido en los medios profesionales y académicos de los países occidentales desde mediados del siglo $\mathrm{XX}$, que, dentro de cinco años, será ya el paradigma común de los historiadores del "siglo pasado".

\section{La revolución historiográfica del siglo $\mathrm{XX}$}

La revolución historiográfica del siglo $\mathrm{XX}$ derrocó, en buena medida, de su pedestal a la historia heredada del siglo XIX: narrativa, acontecimental, política, biográfica; positivista, descriptiva, historizante; historia desde arriba, superficial, se dijo. Impuso cierta hegemonía conjunta de la escuela de Annales y del materialismo histórico, (29) marginando pero no eliminando a la vieja historia. ${ }^{(30)}$ Estableció un paradigma común y diverso que participaba, no siempre conscientemente, y sacaba su fuerza e inspiración filosófica, de un concepto objetivista de la ciencia, relanzado en esa época, lo cual facilitó a su vez la continuidad directa ${ }^{(31)}$ y, más aún, indirecta del positivismo, influencia difusa y ciertamente ambigua pero mucho más aceptada en la práctica por los nuevos historiadores de lo que parece y, sobre todo, de lo que se dice. ${ }^{(32)}$ ¿Cómo se explica si no la facilidad con que han retornado en la última década los géneros historiográficos tradicionales? El empirismo no es sólo una peculiaridad anglosajona, es una tendencia general de la ciencia histórica, si lo contrastamos con la preocupación por la teoría de la sociología (desde Comte hasta los sociólogos históricos pasando por Weber), la antropología (Claude Lévi- 
Strauss) o incluso la psicología (Jean Piaget). El desinterés hacia la teoría y la preferencia por la inducción no es tampoco una particularidad de Annales (33) (causa pero también efecto de una revolución paradigmática que encontró obstáculos en su camino), sino un mínimo denominador común de los historiadores de profesión. ${ }^{(34)}$ Sin reconocer este trasfondo positivista, inductivista y objetivista, no entenderíamos bien los fracasos y las limitaciones del paradigma conjunto Annalesmarxismo y no valoraríamos justamente sus éxitos. Además ¿no forman parte el positivismo, el materialismo histórico y la escuela de Annales, de un mismo proyecto progresista de la historia que empieza con la Ilustración? Es la contigüidad de los tres paradigmas lo que ha facilitado que funcionen como vasos comunicantes ( $y$ sus diferencias lo que ha posibilitado el trasvase de valores hasta una situación de equilibrio).

Lo que a fin de siglo contemplamos justamente sólo como una victoria más bien parcial del primer gran paradigma común de los historiadores, constituidos en comunidad científica, ${ }^{\left({ }^{35}\right)}$ fue en realidad un paso de gigante respecto a la situación precedente, decimonónica, cuando rivalizan sin ponerse de acuerdo historiográficamente el positivismo y el romanticismo nacionalista, el materialismo y el idealismo, los aficionados y los primeros profesionales de la historia. ${ }^{(36)}$ Tirariamos piedras contra nuestro tejado si no valoráramos la revolución científica que supuso el auge de la nueva historia. ${ }^{(37)}$ A partir del fin de la II Guerra Mundial, la historia alcanzó su mayoría de edad como disciplina académica, concluyó su proceso de profesionalización, se situó entre las ciencias sociales en un lugar preeminente, ganó un extraordinario reconocimiento público a caballo del optimismo de la época hacia el progreso tecnológico y económico y la transformación social subsiguiente, liberó grandes energías que hicieron crecer - hasta el día de hoy- la investigación histórica sobre la base de una alta valoración de la innovación temática y metodológica. Se puede decir incluso que la nueva historia que hemos practicado, si hoy agoniza, es por el éxito alcanzado. Su herencia es incalculable. No sabemos qué sería más grave: dilapidar el patrimonio heredado haciendo tabla rasa, o negar como avestruces las crisis irreversible del paradigma común de la historiografia del siglo XX. Estamos convencidos de que ambos riesgos son evitables si nos habituamos a pensar de manera renovada, esto es, compleja.

\section{Hegemonía conjunta y limitada}

De suerte que el paradigma común plural de los historiadores de la segunda mitad del siglo XX tiene tres componentes, simultánea y relativamente, paradigmas rivales: escuela de Annales, marxismo y neopositivismo. ${ }^{\left({ }^{(3)}\right)}$ La hegemonía conjunta de Annales, y el materialismo histórico, siendo cierta, ${ }^{(39)}$ hay que naturalmente relativizarla bastante, ocupa el centro del escenario, pero no todo el escenario, su mediatización por un empirismo superviviente, amoldado magníficamente a las 
nuevas circunstancias, contradice de tal modo las intenciones antipositivistas de las dos grandes escuelas tendencialmente dominantes en el mundo, que sería un craso error no considerar su presencia, no siempre en la retaguardia de la profesión. Los valores compartidos en cuanto a novedades temáticas, metodológicas y teóricas son provistos por Annales y el marxismo, por este orden; la contribución neopositivista tiene más que ver con el concepto general vigente de ciencia histórica y con el enorme prestigio que siguió teniendo el empirismo en la práctica docente e investigadora de todos los historiadores. El positivismo forma parte del consenso historiográfico actual gracias a esa parte inductivista que existe en todos nosotros y que nos lleva a decir, verbigracia, que lo que hay son "buenos y malos" historiadores. El propio concepto de paradigma común que usamos nos remite más a la práctica de la profesión que a su teoria, y en ese terreno es diñcil prescindir de la dosis habitual de positivismo que, concentrado en técnicas y métodos, lo hemos visto, se adapta flexiblemente a paradigmas y teorias diversos, justamente por su desdén por los compromisos paradigmáticos y las teorías.

Los maestros de los jóvenes historiadores de los años '60 (y de los años '70 en España y en otros países) fueron historiadores tradicionales y positivistas que inculcaron en sus discípulos, y éstos a los suyos (a la manera de antiquísima reproducción jerárquica del saber académico) el gusto por la erudición, por la creencia en la imparcialidad del historiador, el recelo hacia las teorias y filosofias de la historia. ${ }^{(40)}$ Todavía hoy, ¿cuántas veces oímos en las lecturas de tesis a miembros del tribunal de filiación annaliste, e incluso marxista, criticar al doctorando por carencias en las fuentes y la bibliografia utilizadas, exigiendo erudición por encima incluso de originalidad e innovación, interpretación e historia-problema, con lo cual se deforma el significado verdadero de una "tesis"? La aportación del positivismo al paradigma historiográfico del siglo XX está en el interés por los archivos y las llamadas ciencias auxiliares de la historia; ${ }^{(41)}$ por las fuentes y la crítica de las fuentes; por los datos y los hechos; por los casos y el análisis; por las técnicas y la especialización, y, además, el positivismo ha conferido legitimación académica a la nueva historia. No sólo el marxismo, también Annales tiene un origen marginal respecto del poder universitario, ¿habrían podido transformarse ambos movimientos en escuelas hegemónicas en las universidades de muchos países sin la colaboración tácita de los sectores tradicionales del establecimiento académico? El academicismo, la pertenencia a la corporación universitaria supone actitudes, jerarquías y rituales, que son parte de los valores compartidos por los historiadores, ${ }^{(42)}$ más allá de las escuelas e incluso ideologías. ${ }^{(43)}$

El equilibrio paradigmático entre las tres corrientes historiográficas citadas implica influencias, reconocimientos y concesiones mutuas que raramente se explicitan. Pero son normales, hasta los años '70, manifestaciones favorables de los historiadores de Annales hacia el materialismo histórico, ${ }^{(44)}$ y de los marxistas franceses $^{(45)} \mathrm{e}$ ingleses ${ }^{(46)}$ hacia Annales. De hecho ambas escuelas se muestran en esos tiempos compatibles ${ }^{(47)}$ y complementarias. Annales por ejemplo se ha intere- 
sado más por la metodología, las estructuras y la historia medieval y moderna, y el materialismo histórico por la teoría, las revoluciones y la historia contemporánea. Annales ha influido mayormente en los paises del sur de Europa y la historiografia marxista en el norte. ${ }^{(48)}$ El lazo más sólido entre los historiadores de ambas tendencias es, sin duda alguna, la oposición frontal a la vieja historia, positivista y conservadora. ${ }^{(49)}$ La concesión mayor de los historiadores empiristas, que admitieron el predominio público de las grandes escuelas sin dejar de practicar una historia clásica y erudita (habiendo cambiado muchos de ellos, eso sí, la historia política y acontecimental por la historia económica y social), es no arremeter contra el marxismo, cosa que sin embargo sí han hecho los filósofos neopositivistas como Popper.

La interconexión de los tres paradigmas-tradiciones entraña que, como el todo está en cada parte, cada uno de ellos interioriza, adapta y representa, a su modo, el paradigma común. Ahora bien, es obligado advertir la mayor contribución de la escuela de Annales al acervo común de los historiadores occidentales de los años ' 50 y '60, ${ }^{(50)}$ que corresponden con la generación de los segundos Annales, liderada por Fernand Braudel, que culmina los esfuerzos de innovación y rupturas de Marc Bloch y Lucien Febvre, en el período entreguerras, con la historia tradicional. Francia va a ser el centro de la revolución historiográfica del siglo XX por la radicalidad, para bien y para mal, ${ }^{(51)}$ sin parangón en otros países, con que combate y arrincona a la vieja historia historizante. ${ }^{(52)} \mathrm{Ni}$ siquiera nuestra historiografia marxista fue tan dura y neta a la hora de cambiar paradigmas: siguió cultivando y/o aceptando, por ejemplo, una historia política que Annales negaba por principio. ${ }^{(53)}$ La centralidad de Annales (a través de sus enfoques innovadores) en el paradigma historiográfico dominante facilita y vertebra la diversidad de éste, desde el neopositivismo al marxismo estructural. Con todo, en cada país la convergencia historiográfica se produjo de forma distinta: en Gran Bretaña el rol vertebrador de la nueva historia acabó por corresponder a la nueva historiografia marxista.

Pierre Vilar decía, en 1967, que después de cincuenta años de rechazo "la investigación histórica va en el sentido en que Marx la había encausado", gracias a los historiadores como Labrousse y otros, imbuidos por el pensamiento de Marx aunque no siempre lo proclamen. ${ }^{(54)}$ ¿Se puede generalizar este marxismo tácito a toda la escuela de los primeros y, sobre todo, de los segundos Annales? La respuesta es si en el sentido de que los nuevos historiadores franceses consideran - la mayoría lo siguen sosteniendo hoy- que han asumido las enseñanzas científicamente válidas del materialismo histórico. Es un lugar común entre los historiadores contemporáneos, incluso entre algunos tenidos por conservadores, admitir la contribución del materialismo histórico a la construcción de la historia científica sin por ello considerarse políticamente marxistas. Es la prueba más evidente del componente marxista del paradigma común. El prestigio profesional de los historiadores marxistas corrobora el sentimiento general de estar en el mismo barco, aunque se investigue sobre distintos temas y con enfoques a menudo matizadamente 
diversos. La admisión del materialismo histórico en la academia historiográfica, donde ocupó y ocupa posiciones de poder en absoluto desdeñables (lo que obliga a tenerlo en cuenta cientificamente), subraya la autonomía de la ciencia respecto de la política. ${ }^{(55)}$ La pura verdad es que gran parte de la difusión de los conceptos marxistas alcanzada en nuestras universidades es indirecta, consecuencia de la coparticipación de la teoría y la práctica materialista de la historia en el paradigma común de las ciencias sociales y humanas; en contrapartida, el marxismo confiere credibilidad progresista al conjunto hegemónico, del mismo modo que Annales proporciona el prestigio de la renovación y los historiadores positivistas la imagen académica, sobre todo en el momento de acceder al establishment los nuevos historiadores de la economía y de la sociedad, en los años ' 60 y' 70 .

La historiografia española se caracteriza por no haber desarrollado una escuela propia, y por una recepción tardia ${ }^{(56)}$ de la renovación historiográfica del siglo $\mathrm{XX}$ a causa del paréntesis franquista y de la consabida inercia académica, es por ello nuestro pais una excelente ilustración del triple origen del paradigma común implantado en los años ' 60 y ' 70 , entre una y dos décadas después que Francia. A lo largo de 1975 un grupo de historiadores jóvenes, y menos jóvenes, escriben sobre la situación y perspectivas de la historia, en el Boletin Informativo de la Fundación Juan March, delimitando claramente las tres contribuciones que protagonizan, por activa o por pasiva, la renovación historiográfica:(57) Annales (Antonio Eiras Roel, José Ángel García de Cortázar), marxismo (Juan José Carreras, Antonio Elorza) e historiadores tradicionales (Luis Suárez, José María Jover) que, en los textos que aportan, ${ }^{(58)}$ muestran cierto respeto y apertura hacia las dos corrientes internacionales de vanguardia. Con el paso de los años, a pesar de la crisis del marxismo, el materialismo histórico ha mantenido su influencia en el campo de la historia, al contrario de lo que sucedió con sociólogos, filósofos, economistas y politicólogos: "los historiadores siguen por lo general considerando las tesis principales del materialismo histórico como una bucna herramienta metodológica". (59) Dicho en España - en 1991 - por un filósofo, parece excesiva esta afirmación en términos absolutos pero si es verdadera ${ }^{(60)}$ comparativamente, cabe preguntarse el por qué. La continuidad hasta el presente del mentado paradigma común tripartito como referencia historiográfica básica, a pesar de la fragmentación y crisis de la disciplina, es una parte esencial de la respuesta.

Mientras el epicentro renovador francés se consolida, en la década que sigue a la Segunda Guerra Mundial, ${ }^{(61)}$ en el mundo anglosajón, y concretamente en Inglaterra sigue campando por sus respetos la vieja historia politica. ${ }^{(62)}$ Hasta los años ' 60 y ' 70 no se estabiliza, frente al positivismo dominante (que inclusive se agudiza desde 1900) y con la ayuda de Annales, una historia social de orientación marxista, ${ }^{(63)}$ si bien Peter Burke -en 1984- reconoce que todavía, a pesar del ascenso de la nueva historia cconómica, social, y cultural, la historia política es $\mathrm{cl}$ sector "más densamente poblado", comenzando a integrarse en la nueva historia al desarrollar precozmente una historia social de la política. una nueva historia 
política. (64) Habrá que esperar hasta finales de los años '70 para ver cómo la historia social anglosajona irradia su influjo internacional, al relevar al marxismo (estructuralista) en decadencia en Francia y en los países latinos. ${ }^{(65)}$ El problema de los años ' 80 es la creciente debilidad del paradigma común, contestado interna (incremento multilateral de la rivalidad entre los tres componentes) y externamente; en este contexto, el fruto brillante (verbigracia, las obras de Thompson) pero tardío ${ }^{(66)}$ de la historiografía marxista anglosajona no puda imponerse y suplir el reflujo de la influencia de Annales (que también acabó afectándole), (67) y menos en el ambiente desfavorable de los años ' 80 (neoconservadurismo, retroceso de las humanidades). La historia social inglesa, y norteamericana, maduró demasiado tarde para el viejo paradigma del siglo XX (en cuyo seno se desarrolló), y demasiado pronto para enlazar con el nuevo paradigma hoy en formación. El retraso, y tal vez la moderación, en la ruptura con la historia tradicional ayudan a entender que la historia social angloamericana no fuera capaz de ofrecer nuevas y estables soluciones a los problemas finiseculares, recomponiendo el paradigma común.

$\mathrm{Al}$ igual que Annales, sufre la historia social anglosajona (sobre todo Past and Present), desde finales de los años '70, las preceptivas críticas cruzadas, también desde el marxismo: por perder el espiritu innovador, mostrándose conservadora ante la historia de la familia, la historia de las mujeres, la historia oral...; ${ }^{(68)}$ por abandonar la historia de la política, ${ }^{(69)}$ los enfoques cualitativos y la historia-problema; ${ }^{(70)}$ por ser débiles ante la tradición whig de la historiografia británica, moralista liberal y positivista. ${ }^{(71)}$ Tomando en consideración éstas y otras críticas, a los movimientos que han nucleado tanto Past and Present como Annales, en total al paradigma común, y con pretensiones siempre consuructivas, hemos esbozado ya en otro lugar nuestra alternativa. ${ }^{(72)}$

\section{Escisión objeto/sujeto}

La revolución historiográfica del siglo XX se planteó - y ciertamente lo logró, ya veremos a qué precio- que la historia fuese admitida entre las ciencias sociales, que al mismo tiempo, desde Comte y pese a Kant, sacaban su cientificidad de las ciencias naturales, bajo el viejo criterio de la unidad del método científico. Este esfuerzo por la homologación científica de la historia con la sociologia, la economía y demás nuevas ciencias sociales, encontró feroces resistencia de filósofos y pensadores que querían representar a las nuevas disciplinas, desde Karl R. Popper ${ }^{(73)}$ hasta Claude Lévi-Strauss ${ }^{(74)}$ pasando por Jean Piaget, ${ }^{(75)}$ que los nuevos historiadores conjuraron tratando de parecerse lo más posible a las ciencias sociales $y$, en último término, a las añejas ciencias naturales, potenciando una "imparcialidad" objetivista y centrando las escasas reflexiones en la metodologia, campo de jucgo preferido del positivismo. Se perdió así la ocasión de representar "un correctivo benéfico frente al provincialismo regional, temporal y objetivo de la investiga- 
ción social dominante".(76) Paradójicamente, Kuhn tiene que aplicar la historia para "despositivizar" la filosofia de las ciencias naturales, propiciando de este modo un cambio de paradigmas que ha llegado a las ciencias sociales y a la propia historia, al menos tal es nuestra intención.

En el camino que va del inductivismo ingenuo de Newton y Galileo a la ciencia positiva de Augusto Comte, hemos dejado atrás la teología y la metafísica, la superstición y el dogmatismo, como formas de conocer "auténticamente" el mundo objetivo, aquello que existe fuera de nosotros mismos. No es poca cosa. Para lograr esta meta prioritaria, la ciencia moderna e ilustrada - antes de convertirse a su vez en dogmatismo laico, cientificista-, ${ }^{(77)}$ para conocer los hechos "tal como sucedieron" - diría el gran maestro de los historiadores positivistas, Ranke - sin acudir a lo sobrenatural, ha eliminado de un modo u otro el sujeto, y no sólo el sujeto trascendente, también el sujeto humano. A los científicos de los siglos XVII-XIX sería anacrónico pedirles más: la ciencia tenía que pasar por su fase objetivista depuradora. Ahora bien, eno se ha prolongado demasiado este concepto tradicional de ciencia a lo largo del siglo XX? ¿No es absurdo que la historia siga fiel -o infiel, según se mire - al concepto mecanicista y positivista de la ciencia a finales del siglo XX?

La ciencia occidental al afirmar que los objetos (inmutables, autosuficientes) existen independientemente del sujeto (que perturba e induce a error), hizo posible la observación de la naturaleza y su explicación mediante la experimentación y la verificación, dio lugar a avances colosales del conocimiento humano. El divorcio cartesiano entre el saber objetivo y el saber subjetivo genera dos maneras, en su momento irreconciliables, de pensar la modernidad: materialismo pasivo e idealismo activo. Sabemos que el objeto y el sujeto son indisociables, pero la ciencia racionalista nos obliga a separar y elegir: o bien ciencia objetivista, o bien filosofia subjetivista (en historiografia, romanticismo en el siglo XIX y presentismo en el siglo XX). Pensar juntamente objeto y sujeto requiere un giro de $180^{\circ}$ en nuestro concepto de ciencia. Esto es, una radical puesta al día que mire a la nueva física, pero que también deshaga el camino andado y vuelva a reflexionar sobre la tesis de Marx sobre Feurbach, donde se critica el materialismo "que sólo concibe el objeto, la realidad, la sensorialidad, bajo la forma de objeto o de contemplación, pero no como actividad sensorial humana, como práctica, no de un modo subjetivo. De aquí que el lado activo fuese desarrollado por el idealismo, por oposición al materialismo, pero sólo de un modo abstracto". (78)

El énfasis en lo subjetivo del materialismo histórico, entendido como filosofia de la praxis, contrasta con el postulado objetivista del mismo Marx que dice que "el ser social determina la conciencia", lo que lleva a un filósofo popperiano a situar a Marx, después de Popper y Lakatos, en un apartado sobre el objetivismo de la ciencia. ${ }^{(79)}$ Puede sonar extraño, toda vez que conocemos las motivaciones antimarxistas de Popper, pero no lo es tanto si caemos en cuenta que ambos son consecuencia diversa de una misma tradición científica, la diferencia está en que el 
autor de la Miseria del Historicismo no vacila, no permite una doble lectura como Marx, y así escribe consecuentemente, en 1979: "El conocimiento en sentido objetivo es un conocimiento sin conocedor, es conocimiento sin sujeto cognoscente". ${ }^{80}$ En 1973, era Lévi-Strauss quien aseguraba que las ciencias sociales y humanas, si "son verdaderamente ciencias", deben mantener el dualismo del observador y su objeto, postulado por las ciencias exactas y naturales, recalca el máximo teórico y difusor del estructuralismo, ${ }^{(81)}$ ajeno a las consecuencias epistemológicas para las ciencia sociales de los descubrimientos contemporáneos en física y biología. Estamos ante una de esas anomalías de Kuhn - ejemplos en contrario- con que se encuentra el paradigma dominante, sin que por el momento haga demasiada mella en sus valedores. ${ }^{(82)}$ Comprobamos, pues, la sorprendente vigencia del objetivismo del paradigma naturalista de los años '70, cuando el paradigma compartido por los nuevos historiadores estaba en su plenitud. En 1977. Kuhn se pregunta, y nosotros con él: "cómo es que los filósofos de la ciencia han descuidado durante tanto tiempo los elementos subjetivos". ${ }^{(83)}$ La verdad es que en la segunda mitad del siglo $\mathrm{XX}$, antes de Kuhn, en filosofia de la ciencia el paradigma era Popper y sus epígonos - desde La sociedad abierta y sus enemigos (1945) - y en ciencias sociales se impuso el objetivismo estructuralista; si a ello unimos el peso del economicismo marxista, potente en la segunda posguerra, tenemos una buena explicación de por qué perduró tanto tiempo el objetivismo de la ciencia propio del siglo XIX, con todas las matizaciones que se quieran, concretamente en la disciplina de la historia, condicionada por un empirismo latente de origen decimonónico en mayor grado que las nuevas ciencias sociales.

Otras características de este paradigma científico objetivista activo en la posguerra, que sobredeterminan asimismo el bienintencionado paradigma historiográfico Annales-materialismo histórico, son el sentido absoluto (no condicionado por un sujeto) de su noción de verdad y el principio metodológico de la simplicidad.

La máquina determinista de Newton es perfecta, está sujeta al orden absoluto, porque es obra de Dios; Kant sustituirá al Dios absoluto por la Razón absoluta, pero el resultado es el mismo: la verdad objetiva de la ciencia ilustrada es un atributo trascendente, un objetivo utópico, en su totalidad está fuera del alcance del sujeto cognoscente. Esta dimensión idealista de la verdad científica ha contribuido grandemente a arruinar la puesta en práctica de un concepto paradigmático clave de Annales y del marxismo: la historia total. Para los depositarios de estas verdades absolutas, resulta lógicamente inconcebible la existencia de un paradigma común, un lugar donde se comparten valores, métodos, líneas de investigación y conceptos con escuelas rivales.

Este orden perfecto, objetivo y absoluto, hay que hallarlo debajo de la apariencia desordenada de la realidad, a través de una metodología fundada en la simplificación. ${ }^{(84)}$ No cabe dudar de la fecundidad del pensamiento científico que separa lo que está ligacio (disyunción) y unifica lo que es diverso (reducción), selecciona y 
jerarquiza, clasifica y cosifica, una realidad que, conforme avanza, la propia investigación empírica entrevé más compleja, relativa y global en su contenido. El acto primigenio de la racionalización simplificadora de la ciencia moderna ha sido, pues, la escisión objeto/sujeto. El éxito de los nuevos paradigmas científicos dependerá, entre otras cosas, de su capacidad para superar la metáfora que encierra dicho corte conceptual y concebir la realidad — también la realidad histórica- como simultáneamente objetiva-subjetiva.

\section{Sobredeterminación}

Los condicionamientos objetivistas que los paradigmas científicos predominantes han ejercido sobre la nueva historia, desde el viejo positivismo al estructuralismo de los años ' 60 , acabaron potenciando sus tendencias más economicistas y cuantitativistas, y arrinconando gravemente la doble dimensión subjetiva de la historia (el sujeto como agente histórico y el historiador como sujeto epistémico) provocando, al filo del nuevo siglo, una formidable crisis de identidad.

El marxismo influye contradictoriamente en el paradigma común de los historiadores, sólo muy tardíamente en el sentido antes citado de las tesis sobre Feurbach. Los historiadores marxistas ingleses se interesarán por el sujeto social (el cambio y las revoluciones que, por la misma época, guiaron a Kuhn) y cultural (el materialismo cultural de Thompson) a contracorriente - y como reacción- de una generalizada lectura objetivista del marxismo cimentada en el positivismo evolucionista, primero, y en el estructuralismo atlhusseriano, después.

Tom Bottomore considera al Círculo neopositivista de Viena, que florece entre las dos guerras mundiales, y cuya labor continúa en gran medida Popper en la segunda posguerra, como "la tendencia más influyente de la filosofia de la ciencia del siglo XX", y explica cómo uno de los representantes más prominentes, Otto Neurath, anima un marxismo positivista (que por lo demás flota en el ambiente) consistente en una simbiosis de sociologia empírica, ideología tecnocrática y evolucionismo "por etapas" que sirve de apoyo teórico al revisionismo de la II Internacional ${ }^{(85)}$ y que nutre, asimismo, al estalinismo con su tosco determinismo y el desarrollismo de los planes quinquenales. ${ }^{(86)}$

La vía política vehicula el ascendiente, desde fuera, de este marxismo empirista en los nuevos historiadores: es conocida la militancia activa en los partidos comunistas de la posguerra, de la mayoría del grupo fundador de Past and Present ${ }^{(87)}$ y de miembros prominentes de la escuela de Annales (Friedmann, Furet, Le Roy Ladurie), o en los partidos socialistas (Labrousse, incluso Febvre); el reconocimiento moral de los intelectuales hacia los comunistas y la URSS por su aportación a la lucha contra el nazi-fascismo, también cuenta para comprender este influjo "desde fuera". Frente al poder político del marxismo positivista oficial poco pudo el marxismo crítico de la escuela de Francfort, desarrollado asímismo en los años 
'20 y '30, y continuado hasta hoy por Habermas. El optimismo económico y desarrollista de la posguerra favorece, en último extremo, un marxismo triunfal (que se va extendiendo desde el Elba hasta el Mar de China) que cree: en la determinación "en última instancia" de la superestructura por la base económica y tecnológica de la sociedad; en una ideología reducida a "falsa conciencia", reflejo distorsionado de la realidad objetiva; en la necesidad inexorable que conduce, etapa tras etapa, la humanidad hacia el comunismo pasando por el esclavismo, el feudalismo, el capitalismo y el socialismo. En la práctica, más allá de las citas rituales en los manuales, se olvida el Marx subjetivo (la dialéctica; eso de que la historia la hacen los hombres; la lucha de clases). No olvidemos que los sujetos políticamente activos más importantes son, en ese momento $-\mathrm{y}$ en cierto sentido eso dura hasta 1989 - los dos bloques enfrentados: 1946-1956, la guerra fría; 1956-1963, la coexistencia pacífica. Este es el contexto internacional, cuando se impone académicamente la nueva historia.

Este marxismo sin sujeto se beneficia del clima empiro-objetivista existente en los ambientes científicos, en los años ' 40 y ' 50 - es el momento de la ofensiva neopositivista en el campo de la filosofia de la ciencia-, contrarrestando las aportaciones más creativas de los historiadores marxistas al paradigma común que se generaliza por esos años entre la comunidad de historiadores. Corresponderá al marxismo estructural de Althusser en particular, $y$ al estructuralismo en general, el honor de acabar de separar, tajantemente, a la nueva historia del sujeto, en los fundamentales años ' 60 , con su determinismo intransigente, un auténtico paroxismo del objeto.

La sustitución paradigmática del marxismo positivista por el marxismo estructuralista fue, sea como sea, un relevo necesario. El fin de la parte más dura de la guerra fría, que todo lo tapaba, la desestalinización de Kruschev y la represión de la revuelta húngara, hacen del año 1956 la fecha clave para comprender el desencanto político y anímico de los intelectuales próximos al marxismo: urgía sustituir la creencia positivista en el evolucionismo economicista por algo que reavivase la fe y la esperanza. Louis Althusser se inspira en el estructuralismo para, so pretexto de combatir el agotado positivismo y devolver al marxismo su carácter de ciencia, trasmutar la determinación concreta del dato empírico en la determinación abstracta de la estructura oculta: rebrota el orden simple, perfectamente objetivo, bajo la apariencia compleja ("ideológica") de la realidad. Las estrategias son diferentes, pero hay una base filosófica común entre el positivismo y el estructuralismo: el objetivismo.

A diferencia del positivismo, el estructuralismo es una filosofia de la ciencia que nace, se desarrolla y muere (cuando el sujeto retorna en el '68) en el seno de las ciencias sociales y humanas. Saussure en lingüística, Lévi-Strauss en antropología, Lacan en psicoanálisis, Althusser en marxismo, todos dicen lo mismo: el objeto de la ciencia es descubrir la estructura subyacente y determinante (lenguaje, símbolos, inconsciente, modo de producción). Nadie prescindió tanto del sujeto como 
los estructuralistas; el mayor antropólogo del siglo XX, Claude Lévi-Strauss, llega a escribir lo siguiente: "creemos que el fin último de las ciencias humanas no es constituir al hombre, sino disolverlo". (88) La historia de los hombres es reemplazada por la historia de las estructuras, "la temporalidad bascula hacia la espacialidad":(89) se impone la geohistoria y la larga duración de los segundos Annales. (90)

La parte más subjetivista $-y$ también la empirista en su dimensión historicista- del paradigma común de los historiadores es agredida por el estructuralismo, que en último extremo niega la historia, lo cual provoca rèspuestas. En 1967, latente ya el reflujo del estructuralismo, ${ }^{(91)}$ Pierre Vilar participa en una mesa redonda con los althusserianos, critica el fondo antihistórico del estructuralismo pero de una manera tan moderada y sincrética que se demuestra así el arraigo alcanzado por el paradigma estructuralista en los nuevos historiadores de la época; es Robert París y otros quienes defienden, más agresiva y explícitamente, el sujeto humano de la historia, acusando al estructuralismo, calificado de discurso academicista, de empobrecer la historia reduciéndola a estructuras inmóviles. ${ }^{(92)}$ En los años '70, al estructuralismo le sucede el posestructuralismo, el marxismo francés entra en decadencia, y a finales de los años '70: sobreviene el relevo anglosajón. E.P. Thompson escribe un libro muy combativo, The Poverty of Theory (1978), contra Althusser, ${ }^{(93)}$ y sus epígonos ingleses Hindess y Hirst (y por elevación contra la revista New Left Review, editora de Althusser), denunciando la esterilidad abstracta del estructuralismo, pero es ya demasiado tarde, el estructuralismo marxista ya no es enemigo en los años ' $80,{ }^{(94)}$ y si me apuran tampoco el marxismo, al menos si se compara con su influencia intelectual y política en las dos décadas anteriores.

En los tiempos de los primeros Annales (1929-1945), el factor virtualmente sobredeterminante es la influencia difusa y ambigua del ciego positivismo: ${ }^{(95)}$ se lucha en Francia contra la historia episódica de Langlois y Seignobos, basada en la servidumbre a los textos, y contra la "ciencia pura" del positivismo, pero también se critica, en un contexto más internacional, el presentismo de Croce y Collingwood que exacerba el rol del sujeto-historiador y la metafisica cíclica de Spengler y Toynbee; ${ }^{(96)}$ batallas que, se quiera o no, son continuación de las antes libradas por el positivismo (sobre todo alemán) en favor de un método científico, crítico. Es por ello que en los fundadores de Annales encontraremos llamadas al objetivismo metodológico, ${ }^{(97)}$ junto con las conocidas posiciones relativistas, humanistas y subjetivistas, ${ }^{(98)}$ todo ello muy propio de historiadores renovadores pero fieles al oficio: enemigos tanto de la simplificación abstracta como de la reificación del objeto-texto. Siempre es posible, en consecuencia, una doble lectura de Annales: objetivista (historia económica, demografia histórica, monografias regionales, historia serial) o subjetivista (historia de las mentalidades, historia humana, historiaproblema, pasado/presente/futuro); Bloch y Febvre mantuvieron cierto equilibrio en sus obras entre la historia económico-social y la historia de las mentalidades (sin que desaparezca del todo el polo de la temática tradicional: verbigracia, la biografia de Martín Lutero de Lucien Febvre), pero conforme va ganando hegemonía la 
nueva escuela, se decanta: primero hacia la historia económica y social estructural (segunda generación, 1945-1968), y después hacia una historia de las mentalidades alejada de lo social ${ }^{(99)}$ (tercera generación, 1968-1989). Cambios paradigmáticos tan radicales que, para explicarlos, no son suficientes los factores externos, hay que abordar las deficiencias internas del propio paradigma fundador annaliste, cuyas dificultades congénitas, epistemológicas y metodológicas, para garantizar la síntesis y un enfoque unitario de la disciplina, son por supuesto extensibles y comunes al materialismo histórico. ${ }^{(100)}$ En ambos casos, la infravaloración o eliminación del sujeto, afecta naturalmente tanto al sujeto-agente (los hombres) como al sujeto-observador (el historiador).

El Marx de las Tesis sobre Feuerbach (1845), que define su pensamiento como la filosofía de la praxis, o del Manifiesto Comunista (1848), que postula que la historia de la humanidad es la historia de la lucha de clases, contradice al Marx del prólogo de 1859 a la Contribución a la crítica de la economia política, que resume su filosofia afirmando que los hombres contraen relaciones económicas, independientemente de su voluntad, que determinan la vida social, política y espiritual, de modo que no es la conciencia lo que determina la vida social y económica sino el ser social lo que determina la conciencia; ${ }^{(101)}$ el Marx joven y humanista de los Manuscritos filosóficos (1844) contradice asimismo al Marx economista maduro de los Crundrisse (18571858 ) y de El Capital (1867-1875); etc.

Políticamente el marxismo pasó, brevemente, a comienzo del siglo $\mathrm{XX}$, del objetivismo positivista de la II Internacional al subjetivismo voluntarista de la III Internacional (para retornar, de otra forma, a lo anterior con Stalin). En el plano intelectual, y más recientemente, está bien representada la doble lectura del marxismo mediante las posiciones de Althusser y de Thompson, por ejemplo.

Como en los primeros Annales, tenemos, pues, dos virtuales lecturas del marxismo, subjetivista y objetivista, de imposible conciliación en la práctica (a ella nos remitimos para verificarlo), problema que se extiende, con mayor razón, al componente positivista - la madre del cordero de este problema epistemológico- de un paradigma común plural que manifiesta, de este modo, su punto más vulnerable, el origen de muchas de sus derrotas.

En principio la historia, ciencia del cambio, se debería prestar mal a este renovado enfoque objetivista, sea economicista sea estructuralista, pero la práctica de la disciplina lo desmiente porque es decisivo el afán $-\mathrm{y}$ la necesidad- de semejarse - de homologarse- a las otras ciencias, naturales y sociales. Por todo ello, estamos convencidos de que no habrá una visión más coherente y unitaria - menos bipolar y pendular - del marxismo, de Annales, del paradigma común de los historiadores, hasta que el paradigma general del sistema de las ciencias no sea capaz de unificar y articular el objeto y el sujeto, lo simple y lo complejo, lo absoluto y lo relativo: los nuevos paradigmas científicos avanzan ya esta dirección.

Va a ser en los tiempos de los segundos Annales (1945-1968), al fusionarse la aportación marxista(102) y annaliste, cuando el influjo "exterior" sobre la escuela 
francesa será mayor. Podemos decir que la coyuntura desarrollista de la posguerra, el marxismo oficial y el estructuralismo antropológico, ayudaron a nacer una segunda generación de Annales, movimiento que está ya marcado por el economicismo $^{(103)}$ y el cuantitativismo. Para librarse de la acusación de empirismo, lanzada contra la historia por Lévi-Strauss y Althusser, Annales se hace estructuralista (el paradigma-ejemplo, la obra maestra, es el Mediterráneo de Braudel, publicado en 1949), sacrificando la historia humana y el cambio social, por la geohistoria, la estructura económica y la larga duración; eso sí, sin caer en la modelización abstracta ni en el teoricismo, esto es, conservando el componente práctico-empirista de la historia, trabajando con hechos y documentos, diferenciándose en suma del estructuralismo ahistórico de Lévi-Strauss y Althusser. En 1980, Pierre Vilar hace girar todavía su concepto de la historia alrededor del concepto de estructura. (104)

Los efectos más evidentes, después de 1945, del substrato positivista, la coyuntura economicista, la vulgata marxista y la sobredeterminación estructuralista, en los valores compartidos por los historiadores científicos son: a. la marginación de la historia de las mentalidades (sujeto mental) en favor de una historia económica; b. la marginación de los conflictos y revueltas (sujeto social) en favor de una historia social estructural; y c. la marginación de los métodos cualitativos en favor de una historia cuantitativa, serial. De ahí el desarrollo tan tardío de la historia de las mentalidades de Annales y de la historia social de Past and Present. De ahí que detectemos evidentes desfases entre los comúnmente aceptados paradigmas-ejemplos y su puesta en práctica: ni siempre son seguidos, ni menos aún son eficazmente emulados los clásicos más complejos y más "venerados", como la Sociedad feudal de Bloch o La formación de la clase obrera de Thompson. Se podría decir que el paradigma común de los historiadores del siglo $\mathrm{XX}$, a pesar de las apariencias, triunfó muy parcialmente, no pudo desarrollarse plenamente, por razones objetivas, pero entraríamos en contradicción con lo que venimos denunciando si nos quedamos ahí: el problema está también en nosotros mismos, existen razones subjetivas, anomalias que afectan a los paradigmas fundacionales, debemos optar por intentar resolverlas con la vista puesta en el futuro inmediato, en el siglo XXI.

\section{Notas}

(1) Este trabajo ha sido redactado antes de "La historia que viene", incluido en Carlos Barros (ed.), Historia a Debate. I. Pasado y Futuro, Santiago de Compostela, 1995, págs. 95-117.

(2) Thomas S. Kuhn, La estructuru de less rooturiones rientificas, Méjico, 1975 (Chicago, 1962), pág. 98.

(3) Idem, pág. 3; en los últimos treinta años han perdido fuerza las afirmaciones de Kuhn acerca de que la peculiaridad de las ciencias sociales respecto de las ciencias naturales consiste en su mayor relación con la sociedad a la hora de elegir temas de investigación (idem, pág. 254) : ramas de la biología y de la 
química relacionadas con la salud y el medio ambiente están hoy, por ejemplo, tan o más conectadas con las necesidades sociales que las ciencias sociales.

(4) Ni qué decir tiene que no todos los filôsofos de la ciencia comparten esa opinión, es por eso que la teoria de Kuhn tiene un sentido para los historiadores que no tienen las aportaciones de Popper o, incluso, de Lakatos.

(5) La tensión esencial. Estudios selectos solre la tradición y el cambio en el ámbilo de la ciencia, Méjico, 1983 (Chicago, 1977), págs. 27-28.

(6) "Aunque mi identidad profesional es la de historiador de la ciencia, lo que pienso cuando me introduzco en el tipo de asunto de que me ocupo en el presente simposio es, en última instancia, epistemología. Deseo realmente saber qué cosa es el conocimiento", Segundos pensumientos sobre paradigmas, Madrid, 1978 (Illinois, 1973), pág. 83.

(7) La estructura, págs. 149-317.

(8) La tensión esenciah pág. 15.

(9) Idem, págs. 10, 32-33, 39-42.

(10) Idem, pág. 10

(11) La pluralidad y complejidad del contenido conlleva algo que confunde a los no avisados: todo paradigma está formado de ouros paradigmas.

(12) La estructura, págs. 279-280.

(13) Segundos pensamientos, pág. 40.

(14) Idem, pág. 13.

(15) Idem, pág. 14.

(16) La estructura, pág. 318.

(17) Idem, págs. 43, 81-82, 199.

(18) La tensión esenciah, pág. 22.

(19) Segundos pensamientos pág, 68.

(20) La función del dogna en la investigación cientificu, Valencia, 1979 (Nueva York, 1963), pág. 18.

(21) La estructura, págs. 284, 318.

(22) Idem, pág. 113.

(23) Idem, pág. 89.

(24) Idem, págs. 276, 277.

(25) Idem, pág. 90.

(26) Los libros de texto, con todo, juegan un papel más importante - casi exclusivo- en las ciencias naturales que en las ciencias sociales, donde el estudiante tiene pronto acceso a antologias de fuentes, investigaciones monográficas y obras clásicas, La tensiön esencial, págs. 251-252; La estructura, págs. $254-255$.

(27) La estructura, págs. 212-216.

(28) El propio Kuhn reconoce, en general, que los historiadores de la ciencia prestan mucha más atención a los cambios de paradigma, descuidando considerablemente los periodos de ciencia normal que ocupan la mayor parte de la vida de los científicos, In función del dogma, pág. 26.

(29) El Congreso Internacional de Ciencias Históricas de París en 1950 marca la asunción de la escuela de Annales, y el Congreso de Moscú en 1970, que batió el récord de historiadores inscritos, la aceptación de la historiografia marxista como parte de la ciencia histórica, Eloy Benito Ruano, El Comité Internucional, el Comilé Español y los Congresos Internacionales de Cienrias Histónicas, Madrid, 1990, págs. 16, 20.

(30) La historia tradicional, empirista, continuó particularmente viva en Estados Unidos y en Alemania, por ejemplo, y, en cierto sentido, también en la práctica de la nueva historia.

(31) El programa del Congreso Internacional de 1950 es el de la nueva historia (demografia, historia económica y social, historia de las mentalidades) más dos secciones dedicadas a la historia institucional y a la historia política.

(32) Annales lo empieza a reconocer desde finales de los años '70; Jacques Revel y Roger Chartier: “este empirismo voluntario, consciente, a contribuido sin duda mucho al dinamismo de los Annales", La nueva historich, Bilbao, 1988 (Paris, 1978); Jacques Le Goff: "Soyons justes. Ce renouvellement que s'est souvent fait contre l'histoire médiévale traditionelle a été en partie permis par les productions de celle-ci. Les 
méthodes erudites, les éditions de cartulaires et de textes, le travail oú s'est appuyée la nouvelle histoire médiévale, mème si, pour changer notre connaissance et notre vision du Moven Age, elle a dú s'en arranger", L'hislotre en france, Paris, 1990, pág. 57.

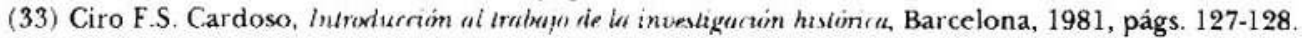

(34) No es nada fácil encontrar relevantes historiadores dc oficio que hubieran hecho aportaciones teóricas significativas al paradigına común de las ciencias sociales.

(35) Partimos de la base de que la primera definición de la historia como ciencia que debemos al positivismo, por falta de partenaires compatibles, no logró generalizarse, a finales del siglo XIX y principios del siglo XX, en la misma medida que después la nueva historia.

(36) La situación de una ciencia es pre-paradigmática cuando pesa más la rivalidad entre las escuelas que las creencias compartidas, Thomas S. Kuhn, Ia funcioin del dogmen, pág. 15.

(37) Estamos empleando aqui la expresión "nueva historia" como sinónimo del paradigma común del siglo XX, esto es, lo contrario de "vieja historia", renovación versus uradición; en un sentido más restrictivo se usa asi mismo para caracterizar la tercera generación de los historiadores de Annules. la nouvelle histonre. (38) Tal vez la corriente neo positivista más representativa sea la Nav History y la Social Scientific History norteamericana

(39) Ciro F. S. Cardoso es uno de los autores que ha reconocido más claramente la confluencia del marxismo y Annales como la base de la reconstrucción de la historia como ciencia, Inlroducción pág. 115. (40) Formación empirista que ayudó también a que los historiadores marxistas occidentales evitaran, en lineas generales, que sus investigaciones fueran ilustración dogmática de una teorización previa.

(41) Cuatro de las doce comisiones internas hoy existentes, del Comité Internacional de Ciencias Históricas hacen referencia a la bibliografia, la diplonática, la metrologia y la publicación de fuentes.

(42) L a École des Hautes Études en. Srienres. Soriales de París todavia mantiene rasgos democráticos vinculados a sus orígenes, como no exigir el titulo de doctor para ser Divecteur d'ètudes (Jacques Le Goff y muchos otros, entre sus miembros, no son doctores y forman sin embargo a futuros doctores), decidir en asamblea la enurada de nuevos investigadores, abrir esta posibilidad a investigadores extranjeros, etc.; normas igualitarias inconcebibles en la Sorbona y en cuaiquiera otra Universidad; aunque debemos reconocer que, en otros aspectos, el paso del tiempo, su encumbramiento y la incorporación de profesores formados en la Sorbona. está imponiendo la jerarquización academicista en la KHEXS:

(43) Sabemos que un académico de izquierdas puede ser tan conservador como uno de derechas.

(44) Marc Bloch, L. Eirunge defatle, París 1946, pág. 189; Lucien Febvte, Prur une histome ì part entièr, París, 1982, págs. 350-366, 665-678; Fernand Braudel, "Historie et sciences sociales: la longue durée", en Annales, 4, 1958, págs. 725-753; Fmanuel Le Roy Ladurie, Le lemlone de l'historien, París, 1973, pág. 17; Jacques Le Goff, Pierre Nora, Presentación de Haier la histumu, I, Barcelona, 1978 (Paris, 1974), pág. 9; Jacques Le Goff, “L'historie nouvelle", La nmuvelle histome, Paris. 1988 (1ra. ed., 1978), pág. 61.

(45) Pierre Vilar, "Historia marxista, historia en construcción", en Hacer la historia op. cit., págs. 197-19. 204-205; Guy Bois, "Marxisme et historie nouvelle", en LAs Nonuelle Hisloriu, op. cit., págs. 255-275; también hubo críticas marxistas, por lo regular dogmáticas contra Annales: Jacques Blot, "Le révisionisme en historie ou l'École des Annules", en I.A Noutiplle Cintiqur, noviembre 1951; Jacques Chambaz, "Le marxisme et l'historie de France", en l.a pensép, noviembre 1953; Michel Grenon, Régine Robin, "Pour la déconstruction d'une practique historique", en Dialertiques, $N^{2} 10-11$; C.S. Ingerflom, "Moscou, Le procès des Annules", en Annules, 1, 1982.

(46) Harvey J. Kaye, Los histonadores manxisias brilinisos, Zaragoza, 1989 (Cambridge, 1984), págs. 205-206; en 1978, Immanuel Wallerstein saluda de modo voluntarista la resistencia de Annules al modo cultural dominante en las ciencias sociales que separa lo político de lo económico, y lo económico de lo cultural, "Annules as Resistance", en Rnnenu, 3/4, 1978, págs. 5-6; en 1985, todavia Hobsbwam defiende Annutes, "ou que resta delá", como interlocutor necesario: "nâo abandonou o horizonte globalizante que partilha com os marxistas, se bem que os seus métodos e as suas posiçiôes ideológicas sejam diferentes", en $l e r$ Históna, Lisboa, 4, 1985, pág. 136.

(47) De no ser así una de ellas hubiera desplazado y marginado a la oura, Thomas Kuhn, La estrurturu, págs. 272, 274. 
(48) Carlos Aguirre Rojas, Construir la histria: entre materialismo histónico y Annales, México, 1993, págs. 9-27.

(49) Carlos Aguirre Rojas, “Convergencias y divergencias entre los Annales de 1929 a 1968. Ensayo de balance global”, en Historia Sociah, 16, Valencia 1993, págs. 115-141.

(50) Las fobias nacionalistas, a menudo inconscientes, no siempre lo facilitan; es habitual buscar y encontrar precedentes a la revolución de Bloch y Febvre, pero es conocido que ninguna de esas nuevas historias precursoras tuvo tanta influencia historiográfica internacional por una razón muy simple: no constituyeron una escuela de la envergadura de Annutes, entre otras causas.

(51) También en Francia es donde las limitaciones de la nueva historia se manifiestan con mayor radicalidad.

(52) Por eso lo que diferencia a Francia del resto, es un arrinconamiento mayor de los historiadores tradicionales, aun reconvertidos, y por lo tanto una influencia sobre todo latente e indirecta del positivismo.

(53) J. Obelkevich, "Past and Presente: Marxisme et historic en Grande-Bretagne depuis la guerre", en Le Débuth N²17, 1981, pág. 97.

(54) Althusser, mélorlo histómico e historicismo, Barcelona, 1972 (París, 1968), págs. 20-21.

(55) Autonomía que explica, asímismo, que en los países anglosajones se hayan desarrollado potentes corrientes marxistas en las universidades son el correlato de una influencia política (a diferencia de lo sucedido en la Europa meridional).

(56) Sobre el retraso español: Carlos Barros, "Historia de las mentalidades: posibilidades actuales", en Problemas actuales de la historiı, Salamanca, 1993, págs. $59-61$.

(57) Once ensayos sobre la historia, Madrid, 1976.

(58) Idem, págs. 21-24, 227-228, 233, 236-238, 240, 244-245.

(59) Francisco Fernández Buey, "Marxismo e historia hoy", en Problemus actuales de la historia, op. cit., pág. 220.

(60) Asi y todo, el materialismo histórico se ha aceptado más que aplicado en la historiogrfía española, a decir de los historiadores próximos que han denunciado después "desiertos", "secanos" y "penurias teóricas", vacíos que normalmente son ocupados por el empirismo; Perry Anderson cree que la debilidad teórica del marxismo español es consecuencia de la ausencia de una tradición filosófica general (Consideruciones, pág. 40, n 4), pero eso es sólo una parte del problema, habría faltado también la amplitud de miras que tuvieron, por ejemplo, Marx y Gramsci para inspirarse en "idealistas burgueses" como Hegel y Croce.

(61) En 1946 se constituye la V Secrión de L'École P'rartique des Harutes Études, iniciándose la fase institucional de la escuela, y reanuda su publicación la revista Annales con nuevos bríos.

(62) Peter Burke, "La historiografia en Inglaterra desde la Segunda Guerra Mundial", en La historiografia en Ocridente desde 1945, Pamplona, 1985, pág. 20.

(63) Peter Burke, "Reflections on the Historical Revolution in France: The Annales School an British Social History", en Reviezu, 1, 3/4, 1978, págs. 147-151; Xavier Gil Pujol, Receprión de la escuela de Annules en la historia social anglosajona, Madrid, 1983, pág. 35.

(64) "La historiografia en Inglaterra desde la Segunda Guerra Mundial", págs. 26-28.

(65) Perry Anderson, Comsideraciomes solte el marxismo occidentah Madrid, 1979 (Londres, 1976), págs. 126-127; Trus las huellas del materialismo histórico, Madrid, 1986 (Londres, 1983), págs. 33-34, 43.

(66) Pensemos que Annates se fundó en 1929 y Plast and Present en 1952, la Apologie pour l'historie de Bloch se publicó en 1949 y What is history? de Carr en 1961.

(67) Y tanto, Thompson reniega, en 1978, de la historia como ciencia prefiriendo su inclusión dentro de las humanidades: "estoy dispuesto a admitir que la tentativa de designar la historia como ciencia ha sido siempre poco provechosa y fuente de confusiones. Si Marx y, más aún, Engels cayeron a veces en este error, entonces podemos disculparnos", Miseria de la temiı, Barcelona, 1981, pág. 68; Perry Anderson contesta acertadamente, apoyándose en la filosofia de la ciencia, en Temia, política e historia. Un debate con E.P. Thompson, Madrid, 1985 (Londres, 1980), págs. 12-13.

(68) J. Obelkevich, op. cit., págs. 106-107,111. 
(69) "Al evitar la historia politica cvitan todo lo esencial para cl desarrollo de la sociedad humana, a pesar de sus pretensiones radicales", Elisabeth Fox, Eugene Genovese, "I a crisis política de la historia social. La lucha de clases como objeto y como sujeto". en Histoma wonal, 1, 1988, pág. 106, otros ven en este marxismo político cierta contınuidad de la historiografia tradicional, empirista y pragmática, o dicho de otro modo, el resurgir del componentc positwista del paradigma comin.

(70) Julián Casanova, Ia hisomi social y los hivomiadores, Barcelona, 1991, pág. 125; resalta este autor como una segunda generación de historiadores marxistas británicos y norteamericanos quiere tomar el relevo de una historia social que se hare inria.

(71) Idem, pág. 1@6.

(72) "I a historia que viene", op. cit.

(73) La meseria del historicismn Madrid, 1984 (1ra. ed. 19441945), pág. 158.

(74) Barry Hindess, Paul Q. Hirts, I're-rafitutist modes of frowhuction, Londres, 1975, págs. 308-313.

(75) Tendencias de ln investigacioin en lu cuencus soristes, Madrid, 1982 (1 ra. ed. 1970), págs. 47-50.

(76) Jürgen Habermas, La reconstrurrion del muterialismo histimei, Madrid, 1986 (Francfort, 1976), pág. 183; la sociologia histórica intenta últimamente satisfacer ese objetivo sin que la comunidad die historiadores haya mostrado demasiada receptividad.

(77) Aiberto Trebeschi, Manual de histerna dei pensamentu carntifico, Barcelona, 1977 (Roma, 1975), págs. $280-281$.

(78) Obras evcogritas, 2, Madrid, 1975, pag. 426; "E.l probiema de si al pensamiento humano se le puede atribuir una verdad objetiva, no es un problema teórico, sino un problema fráctico. Fs en la práctica donde el hombre tiene que demostrar la verdad, es decir, la realidad", ibidem.

(79) Alan F. Chalmers, ¿Qué es esu resa llamstat cienciu?, Madrid, 1989 (1ra. ed. 1976), págs. 169-171.

(80) Idem, pág. 169.

(81) Antropologia estructumb, II, México, 1987 (1ra. ed. 1973), pàgs, 276-277.

(82) Ia extructura, págs. 100-111, 131-135.

(83) In tensióm esenciah pảg. 349.

(84) Edgar Morin, Introdurción al frensammiento complejo, Barcelona, 1994. (París, 1990), págs. 75, 82, 89, $102,144$.

(85) "Ingenieria social" reformista que Popper rebautizará como "tecnología social fragmentaria", Angeles Jiménez Perona, "Racionalidad y método de las ciencias sociales en la obra de Karl R. Popper", en Zona Abrerta, 39-40, Madrid, 1986, págs. 230-237.

(86) Tom Bottomore (dir.), Dircionario del pensumiento marxzsu, Madrid, 1984 (1ra ed. 1983), págs. 596. 597 .

(87) En 1956 abandonan gran parte de clios el Partido Comunista Británico, sin ese distanciamiento con el marxismo realmente existente, ¿podrian haber desarrollado una historiografía marxista no objetivista? la verdad es que todos los grandes marxistas críticos occidentales (I.ukács, Gramsci, Marcuse) fucron heterodoxos políticos respecto del marxismo soviético y aun del marxismo oficial de la mayoria de los partidos marxistas de la época, que no obstante siguieron encuadrando políticamente a muchos historiadores de a pie.

(88) Eil pensamiento saluaje, México, 1964 (París, 1962), pág. 357

(89) François Dosse, Histone du structuratisme, 1, París, 1991, pág. 431

(90) Nunca nos asombraremos lo suficiente de la capacidad de Braudel para hacer que la historia no sólo sobreviviera en contexto tan desfavorable, sino que se situara en cl centro del escenario, pagando un precio, claro cstá.

(91) Idem, pág., 14.

(92) Althusser, método histómico e histemicismu, op. cit., págs 23, 39, 58, 61, 74.

(93) Lo justifica así el autor en 1979: "no fue un acto de agresión, sino un contraataque contra un decenio de rechazo althusseriano", "La política de la teoria", en /hstema popular y teonia sorialisth, Barcelona, 1984 (Londres, 1981), pág. 307.

(94) En 1974, Althusser habia ya publicado su libro Éléments d'intorritique, uraducido al español en 1975 y al inglés en 1976 . 
(95) En 1929 empieza a funcionar el Círculo de Viena, pero no detectamos en la nueva historiografia francesa la influencia del neopositivismo lógico, ni siquiera como adversario.

(96) Lucien Febvre cuestiona acerbamente la filosofia oportunista de Spengler y Toynbee, relacionándola con el ascenso de Hitler, y termina reivindicando la necesidad de homologar la historia y sus métodos a las nuevas ciencias naturales para que así aquélla deje de ser la cenicienta de las ciencias humanas, Combates por la historia, Barcelona, 1975 (París, 1953), págs. 175-217.

(97) "Lo propio del método científico... es abandonar deliberadamente al contemplador, para no querer conocer sino los objetos contemplados", Marc Bloch, Introducrión a la histora, México, 1952 (París, 1949), pág. 117.

(98) "El objeto de la historia es esencialmente el hombre. Mejor dicho los hombres. Más que el singular, favorable a la abstracción, conviene una ciencia de lo diverso, el plural, que es el modo gramatical de la relatividad", Marc Bloch, idem, pág. 25; al definir la historia-problema, Lucien Febvre propone: "Hacer penetrar en la ciudad de la objetividad el caballo de Troya de la subjetividad", Combates por ki historich pág. 43.

(99) Carlos Barros, "Historia de las mentalidades, historia social”, en Historia Contemporínea, 9, Bilbao, 1993, pág. 117.

(100) Este defecto genético es la continuación de la ya analizada escisión objeto/sujeto de la ciencia del siglo XVIl y del positivismo, una prueba más de los cimientos comunes de las tradiciones historiográficas del siglo XX, y un reto para todo nuevo consenso historiográfico.

(101) Karl Marx, Introducrión general a la critica de la eromomía potitica/ 1857, Córdoba, 1974, págs. 76-77.

(102) Hervé Coutau-Begarie: "Aver la deuxième génération, l'influence du marxisme cesse d'être indirecte et inconsciente pour devenir omniprésente", Le phénomène "Nouvelle Historie". Stratégie el idéologie des nouveaux histonens, París, 1983, pág. 235.

(103) En 1946, Georges Lefebvre hace notar el impulso que estaba dando el marxismo a la historia económica, Reflexions pour l'historie, París, 1978, pág. 278; si bien ya en el período anterior a la guerra era tendencialmente mayoritario el contenido económico social en la revista Annales, Charles-Olivier Carbonell, "Evolución general de la historiografía en el mundo, principalmente en Francia", en $L a$ historiografía en Occidente desde 1945, Pamplona 1985, pág. 8.

(104) Iniciación al vocatulario del anailisis histónico, Barcelona, 1980, (Paris, 1980), págs. 49-77. 